Technological University Dublin

DÜBLIN

ARROW@TU Dublin

\title{
Synthesis of Thermally Stable, High Surface Area Anatase-Alumina Mixed Oxides
}

\author{
Suresh Pillai \\ Technological University Dublin, suresh.pillai@tudublin.ie \\ Hareesh US \\ Rajeshkumar s
}

See next page for additional authors

Follow this and additional works at: https://arrow.tudublin.ie/cenresart

Part of the Materials Science and Engineering Commons, and the Nanoscience and Nanotechnology Commons

\section{Recommended Citation}

Kumar, S. R., Pillai, S. C., Hareesh, U. S., Mukundan, P. and Warrier, K. G. K. (2000) Synthesis of thermally stable high surface area anatase-alumina mixed oxides. Materials Letters, 43, 2000, 286-290.

doi:10.1016/S0167-577X(99)00275-X

This Article is brought to you for free and open access by the Crest: Centre for Research in Engineering Surface Technology at ARROW@TU Dublin. It has been accepted for inclusion in Articles by an authorized administrator of ARROW@TU Dublin. For more information, please contact arrow.admin@tudublin.ie, aisling.coyne@tudublin.ie,gerard.connolly@tudublin.ie.

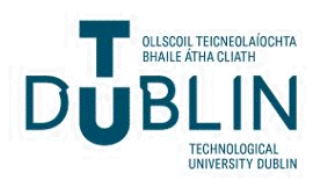




\section{Authors}

Suresh Pillai, Hareesh US, Rajeshkumar s, Mukundan P, and KGK Warrier 


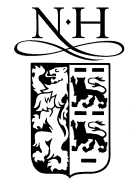

ELSEVIER

\title{
Synthesis of thermally stable, high surface area anatase-alumina mixed oxides
}

\author{
S. Rajesh Kumar, Suresh C. Pillai, U.S. Hareesh, P. Mukundan, K.G.K. Warrier * \\ Regional Research Laboratory (CSIR), Ceramics Division, Thiruvananthapuram 695019, India
}

Received 18 December 1998; received in revised form 26 November 1999; accepted 29 November 1999

\begin{abstract}
Mixed oxides containing anatase and 5-20 mol\% alumina have been synthesized from a precursor sol containing acetic acid modified titanium isopropoxide and boehmite $(\mathrm{AlOOH})$. The resultant oxides retain considerable anatase phase at $1000^{\circ} \mathrm{C}$ and have specific surface area many times higher than that of pure titania. A composite precursor containing titania-20 mol\% alumina after calcination at $450^{\circ} \mathrm{C}$, has a specific surface area as high as $318 \mathrm{~m}^{2} / \mathrm{g}$ compared to a value of $100 \mathrm{~m}^{2} / \mathrm{g}$ for pure titania prepared under identical conditions. The uniform dispersion of the nanoparticles of alumina in the titania gel matrix causes reduction in the anatase/anatase contact points and thus results in a decrease of nucleation sites leading to increase in thermal stability of anatase phase. The high surface area and porosity could arise from the highly branched acetate polymeric gel. The sintered density of compacts derived from mixed oxides is also brought down considerably compared to pure titania counter parts. (c) 2000 Published by Elsevier Science B.V. All rights reserved.
\end{abstract}

Keywords: Sol-gel; Titania; Anatase; Thermal stability; Surface area

\section{Introduction}

Sol-gel titania has received increasing significance recently because of its wide applications in the field of catalysis [1], membranes [2], gas [3] and humidity [4] sensors. $\mathrm{Al}_{2} \mathrm{O}_{3}$ doped $\mathrm{TiO}_{2}$ is reported as a hydrogen gas sensor [5]. Titania membranes are reported to have unique characteristics such as high water flux, semiconductance and chemical stability over other membrane materials such as $\gamma$-alumina, silica and zirconia [6-8]. Titania mainly exists in two forms, anatase and rutile, with a transformation

\footnotetext{
* Corresponding author. Fax: +91-471-491712.

E-mail address: warrier@csrrltrd.ren.nic.in (K.G.K. Warrier).
}

temperature occurring in the temperature range of $600-800^{\circ} \mathrm{C}$ [9-11]. The anatase form is often indicated to be a better photoactive semiconductor in many environmental applications such as air purification, waste water treatment, hazardous waste control [12], and in high temperature catalysis [13]. Therefore, high temperature stable porous anatase form of titania is most desirable in applications such as catalysts and catalyst supports. Many attempts including the sol-gel route have been reported to obtain titanium oxide having above properties [1316]. The anatase-rutile transformation is usually affected by the synthesis conditions as well as impurities [14-16]. The effect of many oxide additives has been investigated and a relationship between the transition temperature and ionic radii of the cations 
has been recently reported [17]. Addition of alumina and silica to titania increases the anatase-rutile transformation temperature to above $1000^{\circ} \mathrm{C}$ [18]. Other oxide additives indicated to raise the anatase to rutile transformation temperature are alumina and zirconia $[19,20]$. Change in oxygen vacancy concentration, formation of solid solution [21], and an exsolution process from the solid solution to rutile and dopant oxide [22] are a few of the many mechanisms proposed for the delayed or enhanced anatase-rutile transformation in presence of dopant oxides. In this process, alumina also restricts the grain growth occurring during the anatase-rutile transition, thus contributing to enhanced porosity. The primary requirement for an effective inhibition of anatase-rutile transition is believed to be a uniform distribution of fine alumina phase in the titania matrix. The reported synthesis methods followed hydrolysis of titanium alkoxide in presence of excess water and incorporation of boehmite [23]. In the sol-gel process, controlled hydrolysis followed by condensation between particles leads to aggregation and results in formation of three-dimensional network of particles. Such precursor gels are often modified by adding chemical modifiers for achieving increased stability [24,25]. Introduction of acetic acid in the titania gel causes an exothermic reaction involving the replacement of isopropoxide groups by chelating acetate groups. The bridging acetate ligands that remain bonded to titanium prevent the hydrolysis reaction effectively by altering the condensation pathway and promoting the formation of linear polymers, which consist of edge shared octahedra [26]. The polymer incorporation forms a highly networked system, which on decomposition, will provide additional microporosities in the final titania particles in addition to what occurs in direct hydrolysis [27]. Therefore, a novel route is proposed in which nanosize sol of boehmite, as source of alumina, is distributed uniformly in a titania precursor containing acetic acid modifier, to synthesize titania-alumina mixed oxides.

\section{Experimental}

Titanium isopropoxide (Aldrich Chemicals, USA) and boehmite sol, prepared from aluminium nitrate (S. D. Fine Chemicals, India) by controlled hydroly- sis as reported earlier [28], were used as the starting materials. The titanium isopropoxide, acetic acid and water were taken in the molar ratio 1:10:100 [14]. In a typical experiment for preparing $5 \mathrm{~mol} \%$ aluminadoped titania, 33.6-g titanium isopropoxide was taken in a beaker, $60-\mathrm{ml}$ acetic acid was added as modifier and the mixture was stirred well for about $30 \mathrm{~min}$. To this solution, $180-\mathrm{ml}$ water was slowly added. The precipitate formed first slowly got dissolved on further addition of water and finally a clear transparent sol was obtained. Stirring was continued for another half an hour. To this solution, $33.689 \mathrm{~g}$ of estimated boehmite sol (equivalent to $5 \mathrm{~mol} \% \mathrm{Al}_{2} \mathrm{O}_{3}$ ) was added and the stirring was continued for another half an hour. Similar procedure was followed for the preparation of 10, 15, $20 \mathrm{~mol} \%$ alumina added samples. In all the experiments, sol was allowed to form a gel on a steam bath. The gels obtained were dried in an electric oven set at $70^{\circ} \mathrm{C}$ over a period of $24 \mathrm{~h}$. Fractions of this gel were calcined at 600,800 and $1000^{\circ} \mathrm{C}$ for $3 \mathrm{~h}$ each. X-ray powder diffraction patterns of calcined samples were recorded in Philips Diffractometer (PW1710). Specific surface area (BET) of the $450^{\circ} \mathrm{C}$ calcined powders were measured (Micromeritics, Gemini model 2360) after degassing the samples at $200^{\circ} \mathrm{C}$ for $5 \mathrm{~h}$. The FTIR spectra of the doped and undoped gels were measured using a Nicolet Magna IR 560 Spectrophotometer in the frequency range 4000 to $400 \mathrm{~cm}^{-1}$ as powders dispersed in $\mathrm{KBr}$ pellets. The gels calcined at $450^{\circ} \mathrm{C}$ were uniaxially compacted to size of $10-\mathrm{mm}$ diameter and 1-mm thickness and were sintered at $1200^{\circ} \mathrm{C}$. Density of the sintered samples was measured by Archimedes principle with water as the reference medium.

\section{Results and discussions}

The FTIR spectra of the precursor gels of titania and titania-boehmite (equivalent to $20 \mathrm{~mol} \% \mathrm{Al}_{2} \mathrm{O}_{3}$ ) are presented in Fig. 1. The bands at 3376 and 3390 $\mathrm{cm}^{-1}$ are common in both the samples and are assigned to the stretching and bending modes of adsorbed water [29]. In the spectra of titania gel (Fig. 1a), the set of two bands observed around 1500 $\mathrm{cm}^{-1}$ are related to bidentate acetate group [14]. The other two bands around 1626 and $1334 \mathrm{~cm}^{-1}$ are $v$ 


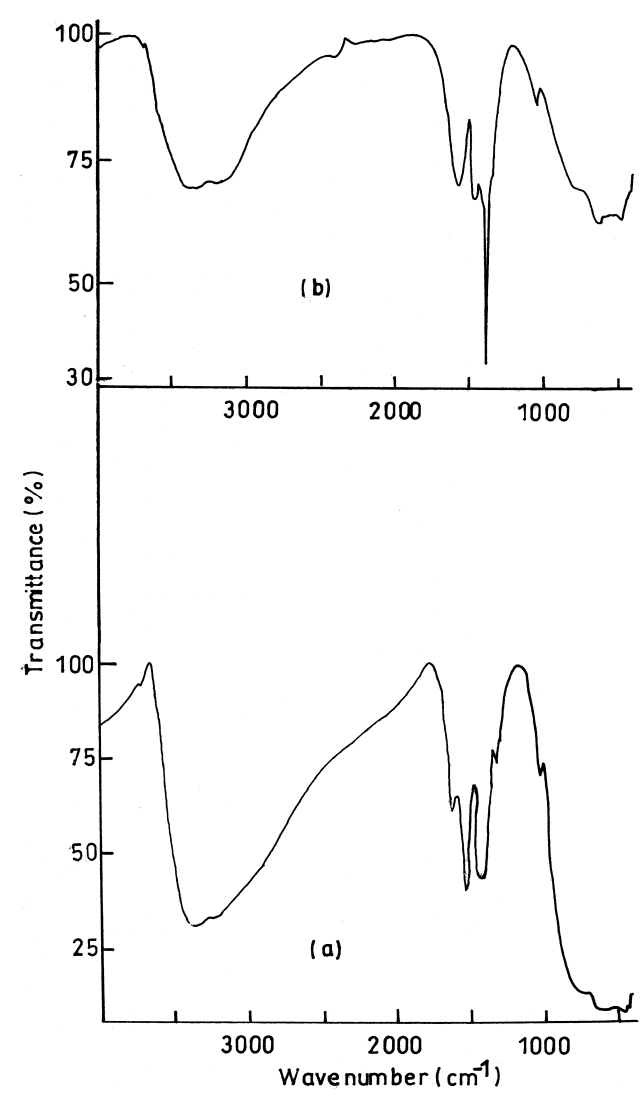

Fig. 1. FTIR spectra of titania precursor gels: (a) without boehmite; (b) with boehmite (equivalent to $20 \mathrm{~mol} \%$ alumina).

COO vibrations due to excess acetic acid. In the spectrum corresponding to titania-boehmite mixed gel (Fig. 1b), all the characteristic peaks of boehmite appear at frequencies 3300, 2099, 1640, 1381, 1036, 632 and $492 \mathrm{~cm}^{-1}$ co-exist with those corresponding to bidentate acetic acid. The polymeric titanium acetate is soluble in excess of water as a result of which a clear sol is obtained. The hydrolysis of chelating acetate groups is relatively slow, and certain acetate groups are still retained in the monolithic xerogel, which can be eliminated on calcination of the gel above $300^{\circ} \mathrm{C}$. Addition of boehmite $(\mathrm{AlOOH})$ is believed to strengthen the gel structure, increase resistance to drying stresses, and result in increased surface area. The surface area of the precursor gels calcined at $450^{\circ} \mathrm{C}$ is given in Table. 1 Titania gel without dopant has surface area of $105 \mathrm{~m}^{2} / \mathrm{g}$ and pore volume of $0.1535 \mathrm{~cm}^{3} / \mathrm{g}$. Usually, acid hydrol-
Table 1

BET surface area and pore volume of samples calcined at $450^{\circ} \mathrm{C}$

\begin{tabular}{llllll}
\hline & \multicolumn{4}{l}{ Alumina content $(\mathrm{mol} \%)$} \\
\cline { 2 - 6 } & 0 & 5 & 10 & 15 & 20 \\
\hline $\begin{array}{l}\text { Surface area } \\
\left(\mathrm{m}^{2} / \mathrm{g}\right)\end{array}$ & 105 & 174 & 240 & 275 & 318 \\
$\begin{array}{l}\text { Pore volume } \\
\left(\mathrm{cm}^{3} / \mathrm{g}\right)\end{array}$ & 0.1535 & 0.2040 & 0.2630 & 0.3073 & 0.3242 \\
\hline
\end{tabular}

ysis of titanium isopropoxide yields a specific surface area of $\sim 50 \mathrm{~m}^{2} / \mathrm{g}$ [26]. The increased surface area of $105 \mathrm{~m}^{2} / \mathrm{g}$ is attributed to the contribution from the modified gel. Addition of $20 \mathrm{~mol} \%$ alumina in the form of boehmite further increases the specific surface area of the mixture of oxides to as high as $318 \mathrm{~m}^{2} / \mathrm{g}$ with a pore volume of $0.3242 \mathrm{~cm}^{3} / \mathrm{g}$. This large enhancement in surface area is not only due to the contribution from the alumina component (usually $\sim 350 \mathrm{~m}^{2} / \mathrm{g}$ ), [25,30] but has been expected to originate from the decomposition of the acetic acid modifier involved in resultant polymeric gel network. The nitrogen adsorption isotherms of the samples with various compositions are given in Fig. 2. The titania gel-derived sample shows a pore distribution consisting of pores in the micro and

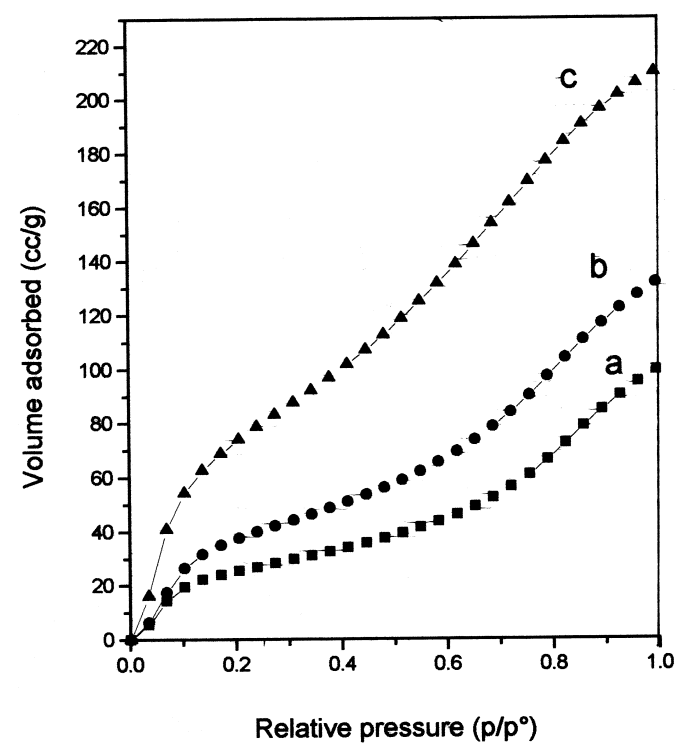

Fig. 2. $\mathrm{N}_{2}$ adsorption isotherms of titania samples with different amounts (mol\%) of alumina: (a) 0; (b) 5; (c) 20. 
Table 2

Crystalline phases and weight percentage of rutile (given in brackets) determined by powder XRD for materials heated to different temperatures.

$\mathrm{A}$ - anatase, $\mathrm{R}$ - rutile.

\begin{tabular}{llllll}
\hline $\begin{array}{l}\text { Temperature } \\
\left({ }^{\circ} \mathrm{C}\right)\end{array}$ & \multicolumn{2}{l}{ Alumina content $(\mathrm{mol} \%)$} & 10 & 15 \\
\cline { 2 - 6 } & 0 & 5 & A, R (94.7) & A, R (88.7) & A, R (63.8) \\
\hline 1000 & A, R (97.4) & A, R (95.6) & A & A & A \\
800 & A, R (93.4) & A & A & A & A \\
600 & A & A & A & \\
\hline
\end{tabular}

meso pore regions. In presence of boehmite, considerable increase in the adsorption occurs which is indicative of very high porosities. The volume of nitrogen adsorbed at a given $P / P_{0}$ value shows a gradual increase with increase of alumina content. Although the adsorption isotherm more or less belongs to Type IV, there appears a distinct influence on pore size distribution by nanosize alumina incorporated in the boehmite form.

The titania precursor with and without the presence of boehmite studied by X-ray powder diffraction indicated a significant rise in temperature of transformation of anatase to rutile phases (Table 2) The weight fraction of the rutile present in the

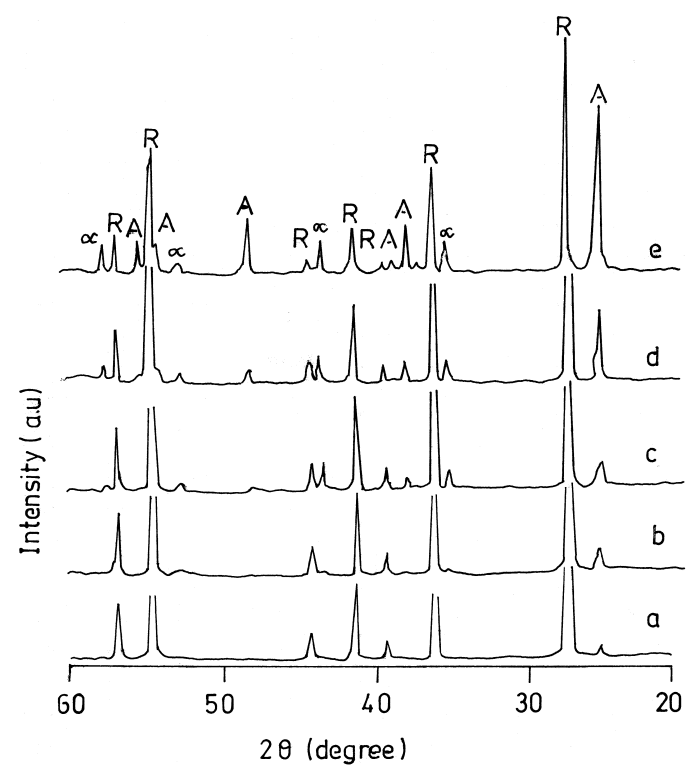

Fig. 3. XRD patterns of titania samples with various amounts (mol\%) of alumina: (a) 0; (b) 5; (c) 10; (d) 15; (e) 20, calcined at $1000^{\circ} \mathrm{C}$ [A - anatase; $\mathrm{R}-$ rutile; $\alpha-\alpha$-alumina]. calcined samples was calculated according to the formula [31]. $W_{\mathrm{R}}=1 /\left[1+0.8\left(I_{\mathrm{A}} / I_{\mathrm{R}}\right)\right], W_{\mathrm{R}}$ is the weight fraction of the rutile present while $I_{\mathrm{A}}$ and $I_{\mathrm{R}}$ are the X-ray integrated intensities of (101) reflections of anatase and (110) reflections of rutile, respectively. All samples heated at $600^{\circ} \mathrm{C}$ show only the anatase phase. At $800^{\circ} \mathrm{C}$, the undoped titania samples show anatase as well as rutile peaks, the rutile weight percentage being $\sim 93 \%$ whereas all alumina-doped titania samples show nearly $100 \%$ anatase phase. At $1000^{\circ} \mathrm{C}$, undoped titania samples show $\sim 97 \%$ rutile (Fig. 3). On increasing addition of alumina to $20 \mathrm{~mol} \%$, the rutile content decreases to about $63 \%$ when calcined at $1000^{\circ} \mathrm{C}$.

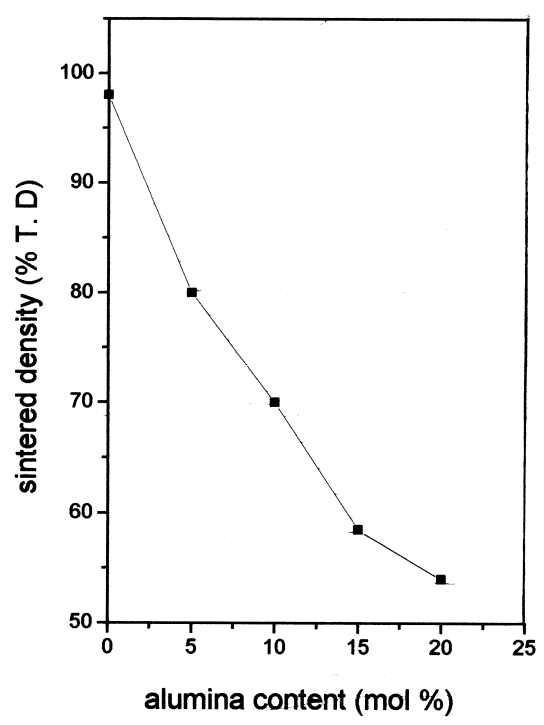

Fig. 4. Variation of sintered density of titania samples with various amounts $(\mathrm{mol} \%)$ of alumina (sintered at $1200^{\circ} \mathrm{C}$ ): (a) 0 ; (b) 5 ; (c) 10; (d) 15; (e) 20 . 
The nucleation and growth processes associated with phase transformation get delayed in the presence of alumina and this promotes pore development in titania. The uniform dispersion of the nanoparticulate boehmite sol in the polymeric titania precursor is considered to have caused reduction in the anatase/anatase contact points thereby leading to enhanced thermal stability. The densification of undoped titania could be done at $1200^{\circ} \mathrm{C}$ and density as high as $98 \%$ was obtained (Fig. 4). With increasing alumina addition, the density decreases and reaches a value as low as $\sim 55 \%$ for $20 \% \quad \mathrm{Al}_{2} \mathrm{O}_{3}$. The decrease in sintered density of titania containing alumina could be due to the fine distribution of $\mathrm{Al}_{2} \mathrm{O}_{3}$ at grain boundaries. There has been no indication of substitution or formation of aluminium titanate in this study at the temperature of densification.

\section{Conclusions}

(1) High surface area titania having specific surface area as high as of $318 \mathrm{~m}^{2} / \mathrm{g}$ has been prepared by incorporating up to $20 \mathrm{~mol} \%$ of alumina in the form of boehmite in a titania polymer precursor.

(2) Addition of alumina has resulted in a shift of the anatase-rutile transformation to higher temperatures by about $200^{\circ} \mathrm{C}$, in agreement with earlier investigations.

(3) Alumina addition has been found to inhibit densification of titania to a larger extent resulting in porous substrates.

\section{Acknowledgements}

The authors (SRK and USH) are grateful to CSIR, Government of India and (CS) to TNO Institute of Applied Physics, The Netherlands, for financial support in the form of research fellowships.

\section{References}

[1] C. Anderson, A.J. Bard, J. Phys. Chem. B 101 (1997) 2611.

[2] K.N.P. Kumar, K. Keizer, A.J. Burggraff, J. Mater. Chem. 3 (9) (1993) 917.
[3] U. Kirner, K.D. Schierbaum, W. Gopel, B. Leibold, N. Nicoloso, W. Weppner, D. Fischer, W.F. Chu, Sensors and Actuators, B 1 (1990) 103.

[4] Y.C. Yeh, T.Y. Tseng, D.A. Cheng, J. Am. Ceram. Soc. 78 (1989) 1472.

[5] L.D. Birkefeld, A.M. Azad, S.A. Akbar, J. Am. Ceram. Soc. 75 (1992) 2964.

[6] S.H. Hyun, B.S. Kang, J. Am. Ceram. Soc. 79 (1996) 279.

[7] D. Beyer, H. Richter, G. Tomandl, Surface and Interface Analysis 25 (1997) 593.

[8] A. Larbort, J. Fabre, C. Gulzard, L. Cot, J. Gillot, J. Am. Ceram. Soc. 72 (1989) 257.

[9] K.N.P. Kumar, K. Keizer, A.J. Burggraff, T. Okubo, H. Nagomoto, S. Morooka, Nature 358 (1992) 48.

[10] A.W. Czanderna, C.N.R. Rao, J.M. Honig, Trans. Faraday Soc. 54 (1958) 1069

[11] U. Balachandran, N.G. Eror, J. Solid State Chem. 42 (1982) 276.

[12] M.R. Hoffman, S.T. Martin, W. Choi, D.W. Bahnemann, Chem. Rev. 95 (1995) 69.

[13] R.R. Besca, M.J. Gratzel, Am. Ceram. Soc. 79 (1996) 2185.

[14] C. Suresh, V. Biju, P. Mukundan, K.G.K. Warrier, Polyhedron 17 (18) (1998) 3131.

[15] X. Ding, L. Liu, X. Ma, Z. Qi, Y. He, J. Mater. Sci. Lett. 13 (1994) 462

[16] A.K. Vasudevan, P.P. Rao, S.K. Ghosh, G.M. Anilkumar, A.D. Damodaran, K.G.K. Warrier, J. Mater. Sci. Lett. 16 (1997) 8.

[17] R.R. Talavera, S. Vargas, R.A. Murillo, R.M. Campos, E.H. Poniatowski, J. Mater. Res. 12 (1997) 439.

[18] J. Yang, J.M.F. Ferreira, Mater. Lett. 36 (1998) 320.

[19] L. Springer, M.F. Yan, in: L.L. Hench, R.D. Ulrich (Eds.), Ultrastructure Processing of Ceramics, Glasses and Composites, Wiley, New York, 1984, p. 464.

[20] J. Yang, J.M.F. Ferreira, Mater. Res. Bull. 33 (1998) 389.

[21] O. Yamaguchi, Y. Mukaida, J. Am. Ceram. Soc. 72 (1989) 330.

[22] J. Yang, Y.X. Huang, J.M.F. Ferreira, J. Mater. Sci. Lett. 16 (1997) 1933.

[23] V.T. Zaspalis, W. van Praag, K. Keizer, J.R.H. Ross, A.J. Burggraaf, J. Mater. Sci. 26 (1992) 1023.

[24] S. Doeuff, M. Henry, C. Sanchez, J. Livage, J. Non-Cryst. Solids 89 (1987) 206.

[25] H.H. Kung, E.I. Ko, Chem. Eng. J. 64 (1996) 203.

[26] C.J. Brinker, D.W. Scherer, Sol-Gel Science, Academic Press, New York, 1990.

[27] A. Makishima, M. Asami, K. Wada, J. Non-Cryst. Solids 100 (1988) 321.

[28] T.V. Mani, H.K. Varma, A.D. Damodaran, K.G.K. Warrier, U. Balachandran, J. Am. Ceram. Soc. 77 (1994) 1597.

[29] G. Krishna Priya, P. Padmaja, K.G.K. Warrier, A.D. Damodaran, G. Aruldhas, J. Mater. Sci. Lett. 16 (1997) 1584.

[30] G.S. Walker, E. Williams, A.K. Bhattacharya, J. Mater. Sci. 32 (1997) 5583.

[31] R.A. Spurr, H. Myers, Anal. Chem. 29 (1957) 760. 